\title{
Escherichia coli POTENCIALMENTE PATOGÊNICA NA CADEIA DE PRODUÇÃO DE QUEIJO ELABORADO A PARTIR DE LEITE CRU
}

\author{
POTENTIALLY PATHOGENIC Escherichia coli IN CHEESE PRODUCTION \\ CHAIN MADE FROM RAW MILK
}

L. F RIBEIRO ${ }^{1} *$, R. A. SATO ${ }^{1}$, G. A. M. ROSSI ${ }^{1}$, C. E. G. AGUILAR ${ }^{1}$, R. P. MALUTA ${ }^{2}$, M. I. M. MEDEIROS ${ }^{3}$, L. A. AMARAL ${ }^{1}$, J. M. FAIRBROTHER ${ }^{4}$

\begin{abstract}
RESUMO
Escherichia coli em alimentos pode indicar contaminação microbiana de origem fecal e, portanto condições sanitárias insatisfatórias. Diversas linhagens são comprovadamente patogênicas aos seres humanos e animais. Assim, a pesquisa laboratorial de Escherichia coli auxilia na detecção do real risco de uma toxinfecção alimentar. Objetivou-se avaliar a presença de E. coli na cadeia produtiva de queijos elaborados a partir de leite cru. Para isso, colheu-se amostras em cinco pequenas propriedades leiteiras, produtoras de queijos elaborados a partir de leite cru, da região do Município de Jaboticabal, nordeste do Estado de São Paulo. Foram analisadas amostras de fezes bovinas, água da sala de ordenha e de manipulação dos queijos, leite, mão do ordenhador, balde ou superfície interna da teteira utilizada na ordenha mecânica, utensílios de produção do queijo, superfície de manipulação, mão do manipulador do queijo, soro do queijo e queijo. Através da reação em cadeia da polimerase (PCR) buscou-se 20 genes de virulência para diferentes $E$. coli patogênicas: patogênica extra intestinal (ExPEC), shigatoxigênica (STEC), enteropatogênica (EPEC), enterotoxigênica (ETEC), enteroinvasiva (EIEC) e enteroagregativa (EAEC). Após análise de 100 amostras (20 amostras de cada propriedade), detectou-se isolados potencialmente ExPEC em leite, fezes, balde, água, tubulação de ordenha mecânica, superfície de elaboração de queijo, balde, peneira e queijo. Além disso, encontrou EPEC em queijos e STEC em leite e fezes. Neste estudo demonstrou-se que cepas potencialmente patogênicas estão presentes na cadeia de produção de queijos elaborados a partir de leite cru, demonstrando falta de higiene em toda cadeia, ou seja, condições sanitárias insatisfatórias. Além disso, a presença de cepas patogênicas no produto final, o queijo, demonstra que este alimento pode apresentar risco à saúde pública.
\end{abstract}

PALAVRAS-CHAVE: GENES DE VIRULÊNCIA, DERIVADOS LÁCTEOS. DOENÇAS TRANSMITIDAS POR ALIMENTOS (DTA). MICROBIOLOGIA DE ALIMENTOS.

AGRADECIMENTOS: FAPESP- auxílio - Processo 2014/13567-1, à Capes pela bolsa concedida e à Capes pelo processo 99999.002567/2014-08

\footnotetext{
'Unesp - Universidade Estadual Paulista "Julio de Mesquita Filho" (UNESP), Faculdade de Ciência Agrárias e Veterinárias (FCAV), Via de acesso Paulo Castellane, s/n, Jaboticabal, São Paulo, Brasil, CEP 14884-900,

2Departamento de Genética, Evolução e Bioagentes, Instituto de Biologia, Universidade de Campinas (UNICAMP), Barão Geraldo, Campinas, Brazil, Cep 13083-970.

${ }^{3}$ Agência Paulista de Tecnologia dos Agronegócios - APTA/SAA-SP, Avenida Rodrigues Alves,40, Bairro: Horto Florestal, CEP: 17030-000, Bauru/SP.

${ }^{4}$ Département de pathologie et microbiologie, Faculté de médecine vétérinaire, Université de Montréal, SaintHyacinthe, 3200 rue Sicotte, Saint-Hyacinthe QC, Canada, J2S 2M2

*laryssaribeiro84@gmail.com
} 